\title{
Corrosion Behaviour of Aluminium Engine Block in 3.5\% NaCl Solution
}

\author{
M. S. Kaiser ${ }^{*}$, Swagata Dutta ${ }^{2}$ \\ ${ }^{1}$ Directorate of Advisory, Extension and Research Services Bangladesh University of Engineering and \\ Technology, Dhaka, Bangladesh \\ ${ }^{2}$ Institute of Appropriate Technology Bangladesh University of Engineering and Technology, Dhaka, \\ Bangladesh \\ Email: "mskaiser@iat.buet.ac.bd
}

Received June 2014

\begin{abstract}
In the present work, the corrosion behavior of aluminium alloy engine block in $3.5 \% \mathrm{NaCl}$ solution was studied. The work was carried out using conventional gravimetric measurements and complemented by scanning electron microscopy (SEM) and X-ray analyzer (EDX) investigations. The results obtained indicate that the main process the alloy undergoes, under the medium of exposure studied, is related to localized corrosion that takes place as a consequence of the process of alkalinization around the cathodic precipitates existing in the alloy. The alloy suffers a process of corrosion localized to the area surrounding the precipitates of the $\mathrm{Al}(\mathrm{Si}, \mathrm{Mg}$ ) and $\mathrm{Al}-\mathrm{Mg}$, which resulted in hemispherical pits. This identification was confirmed by SEM and EDX analysis. No evidence was found of the formation of crystallographic pitting for exposure times up to 54 days. Gravimetric analysis confirmed that with varying exposure periods the weight loss of the alloy increases and the corrosion rate decreases with time.
\end{abstract}

\section{Keywords}

Localized Corrosion, Gravimetric Analysis, Aluminium-Silicon Alloys, SEM, EDX

\section{Introduction}

Owing to their light weight, suitable strength and strong resistance to corrosion, aluminum alloys are used in a broad spectrum of engineering applications. Corrosion is defined as the gradual chemical or electrochemical attack on a metal by its surroundings such that the metal is converted into an oxide, salt or some other compound which results in the loss of strength, hardness, toughness and other desirable mechanical properties which the metal/alloy posses [1]. The corrosion resistance of aluminum is attributed to an exceptionally stable oxide film that forms on its surface. This film is resistant to attack from water and oxygen in a wide range of temperatures and $\mathrm{pH}$ levels, making aluminum alloys useful in a variety of environments. Corrosion by pitting in aluminium alloys is a complex process that can be affected by diverse experimental factors such as the $\mathrm{pH}$, the temperature, the type of anion present in the solution or the physic-chemical characteristics of the passive layer [2]. The

${ }^{*}$ Corresponding author. 
adsorption of aggressive ions such as $\mathrm{Cl}^{-}$into the faults in the protective film, and their penetration and accumulation in these imperfections is considered one of the triggering factors of the process of nucleation of pitting [3] [4]. Other studies have suggested that pits may develop as a result of a process of hydrolysis which gives rise to a local reduction of the $\mathrm{pH}$ which, in turn, impedes the subsequent process of repassivation [5]. In addition, another factor which is associated with the susceptibility of aluminium to pitting corrosion and other forms of localized corrosion is the electrochemical nature of the intermetallic phases [6]. As a result, often the corrosion behavior can be correlated with the difference in potential between the matrix and the intermetallic compounds present in the alloy [7].

In the present paper, the process of corrosion of a commercially available aluminium alloy engine block in $3.5 \%$ $\mathrm{NaCl}$ solution was studied. The research has been directed towards studying the characteristics, condition of formation and morphology of attack. The corrosion analysis was carried out after 54 days immersion in the solution and was investigated by using weight-loss data and complemented by SEM/EDX investigations.

\section{Experimental Details}

The material used in the current study is a commercially used aluminum alloy engine block. The alloy was analyzed both by wet chemical and spectrochemical methods. The chemical composition of the alloy is given in Table 1. The samples of $25 \times 10 \times 3 \mathrm{~mm}^{3}$ size obtained from the aluminium alloy block were used to conduct the tests for studying the corrosion behaviour. The samples were wet-sanded mechanically with SiC papers of 220 and 1200 grit. Before use, the samples were de-greased with ethanol of $99 \%$ purity and then rinsed with plenty of water. Afterwards, they were dried, weighted (initial) different exposure periods up to 54 days. A stagnant solution of $3.5 \% \mathrm{NaCl}$ at $\mathrm{pH} 5.5$ was used as the aggressive medium. Solution was prepared by dissolving $3.5 \pm 0.1$ parts by weight $\mathrm{NaCl}$ in $96.5 \pm 0.1$ parts of distilled water. The solution was heated at $80^{\circ} \mathrm{C}$ for three hours every day. After the designated exposure in the solution medium, the samples were rinsed with distilled water, dried between two tissue papers, and weighted again (final weight, $\mathrm{W}_{\text {fin }}$ ). Weight-loss measurements were made in triplicate and weight loss was calculated by taking an average of these values [4].

$$
\begin{aligned}
& \text { Weight loss, } \Delta W=\frac{\left(W_{\text {int }}-W_{\text {fin }}\right)}{A} \\
& \text { Corrosion Rate, } K_{\text {Corr }}=\frac{(K \times \Delta W)}{(A \times T \times D)}
\end{aligned}
$$

where, $W_{\text {int }}=$ initial weight before immersion, $W_{\text {fin }}=$ final weight after exposure, $K=$ unit conversion constant ( $K=8.76 \times 104$ for the mmpy unit), $T=$ time of exposure (hrs), $A=$ area in $\left(\mathrm{cm}^{2}\right), \Delta W=$ Weight loss (g) and D $=$ density of metal $\left(\mathrm{g} / \mathrm{cm}^{3}\right)$

The specimens for microstructural observation were prepared using standard metallographic techniques; final polishing was done with fine alumina. The etching was done using Keller's reagent $\left(\mathrm{HNO}_{3}-2.5 \mathrm{cc}, \mathrm{HCl}-1.5\right.$ cc, $\mathrm{HF}-1.0 \mathrm{cc}$ and $\mathrm{H}_{2} \mathrm{O}-95.0 \mathrm{cc}$ ). The washed and dried samples were observed carefully in OPTIKA Microscope and some selected photomicrographs were taken. The SEM investigation and EDX analysis were obtained for the surface of aluminium alloy engine block specimens after their immersions in the solution medium for 54 days. The SEM images were collected by using a JEOL scanning electron microscope with an energy dispersive X-ray analyzer (Model: Link AN-10000) attached.

\section{Results and Discussion}

\subsection{Gravimetric Analysis}

Figure 1 depicts the change of weight loss $\Delta \mathrm{W}, \mathrm{mg} \cdot \mathrm{cm}^{-2}$, calculated using Equation (1) as a function of immersion time for aluminium alloy engine block immersed in $3.5 \% \mathrm{NaCl}$ solution. It is clearly seen from Figure 1

Table 1. Chemical composition of aluminium alloy engine block (wt \%).

\begin{tabular}{ccccccccc}
\hline Alloy & $\mathrm{Si}$ & $\mathrm{Mg}$ & $\mathrm{Cu}$ & $\mathrm{Ni}$ & $\mathrm{Fe}$ & $\mathrm{Zn}$ & $\mathrm{Mn}$ & $\mathrm{Al}$ \\
\hline Block & 10.783 & 0.238 & 2.281 & 0.083 & 0.795 & 0.760 & 0.256 & Bal \\
\hline
\end{tabular}




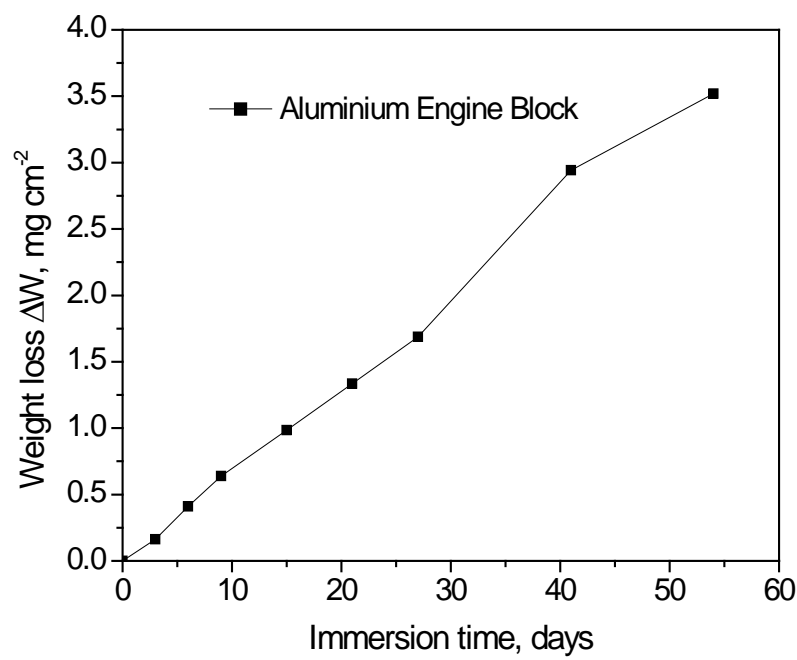

Figure 1. The variation of the weight loss $\left(\mathrm{mg} / \mathrm{cm}^{2}\right)$ as a function of immersion time (days) curve for aluminium alloy engine block immersed in $3.5 \% \mathrm{NaCl}$ solution.

that the value of $\Delta \mathrm{W}$ for the alloy in $\mathrm{Cl}^{-}$solutions increased with increasing immersion time. This is due to the continuous dissolution under the aggressiveness action of the chloride ions to the alloy surface. Although $\mathrm{Al}$ forms $\mathrm{Al}_{2} \mathrm{O}_{3}$ and $\mathrm{Al}(\mathrm{OH})_{2}$ on its surface, its dissolution rapidly increases with increasing exposure time. This is due to the fact that these forms are not compact and not protective and allow the aggressive ions from $\mathrm{NaCl}$ solutions to attack the $\mathrm{Al}$ surface. The values of $K_{\text {Corr }}$, which were calculated from weight-loss tests using Equation (2) for $\mathrm{Al}$ alloy in $3.5 \% \mathrm{NaCl}$ solutions, are plotted against time as shown in Figure 2. It can be seen that, the $K_{\text {Corr }}$ values increased quite abruptly initially until immersion time of 10 days. Afterwards, the $K_{\text {Corr }}$ value decreased with time and attained roughly a constant value. This is due to the accumulation of corrosion products including aluminium oxide and hydroxide, which cover up the surface leading to decrease its uniform corrosion rate.

\subsection{Optical Micrographic Observation}

Figure 3(a) shows the optical micrograph of polished aluminium engine block alloy before immersion into the corrosion medium. The sample has a microstructure characterized by an Al-rich dendritic matrix, $\alpha$-Al phase and a eutectic mixture in the interdendritic region formed by silicon particles, which are coarse and distributed in plate-like morrphology, set in an Al-rich phase [6] [8]. In this type of image the precipitates of $\mathrm{Al}(\mathrm{Mn}, \mathrm{Fe}, \mathrm{Cu})$ are those that appear in the dark tone while those of $\mathrm{Al}(\mathrm{Si}, \mathrm{Mg}$ ) appear in a lighter tone. In Figure 3(b) after removing the samples from the corrosion medium, severe corrosion was observed. These findings primarily suggested that $3.5 \% \mathrm{NaCl}$ can be an aggressive medium to induce corrosion in the aluminium alloy. In order to identify the various types of intermetallic compounds present in the alloy, the samples were studied using SEM and EDX spectroscopy.

\subsection{SEM and EDX Observation}

The SEM photomicrographs in Figure 4(a), show the typical microstructure of the aluminum alloys before the corrosion test. It can be noticed from the figure that $\mathrm{Si}$ is present in dendritic form and mixed homogeneously in Al matrix.

A number of voids and cavities can be seen in the microstructure of the alloy. The alloy contains the $\mathrm{Al}(\mathrm{Mg}$, $\mathrm{Si}$ ) and AlFeSiCu intermetallic phases. The presence of the AlFeSiCu intermetallic with needle-like morphology only was detected during the characterization by SEM and EDX, suggesting that its amount was not detectable by X-ray diffraction. Fe impurities contained in the aluminum account for the formation of this intermetallic phase [8]. The composition of these was then determined by EDX spectroscopy. The results obtained indicate that, particles mainly contain of $\mathrm{Al}(\mathrm{Si}, \mathrm{Mg})$, some Al-Mg intermetallic and few Fe-rich intermetallic phases. 


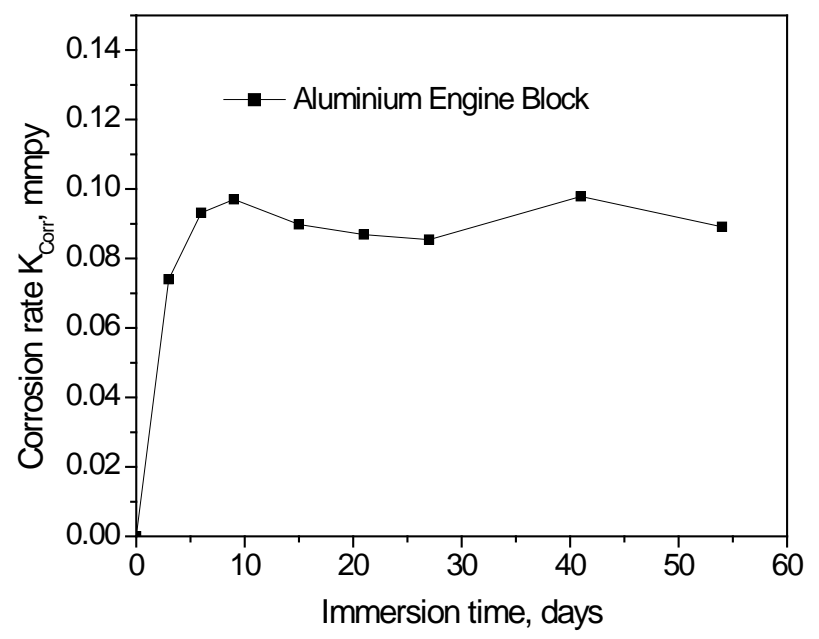

Figure 2. The change of corrosion rate (mmpy) as a function of immersion time (days) for aluminium alloy engine block immersed in $3.5 \% \mathrm{NaCl}$ solution.
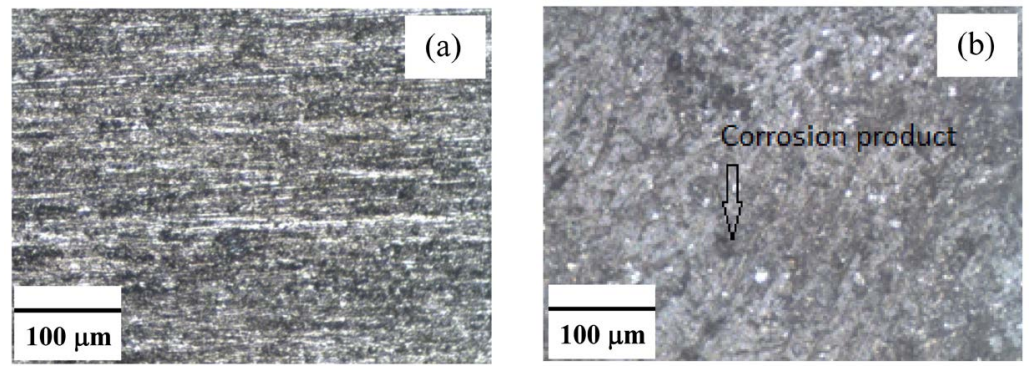

Figure 3. Optical micrograph of polished aluminium alloy engine block (a) before corrosion and (b) after corrosion in $3.5 \% \mathrm{NaCl}$ solution for 54 days.

The EDX profile of $\mathrm{Al}$ (Si, Mg) and intermetallic are shown in Figure 4(b) and Figure 4(c), the weight percentage of the elements found in the selected areas were $1.22 \% \mathrm{Al}, 98.08 \% \mathrm{Si}, 0.45 \% \mathrm{Ni}, 0.26 \% \mathrm{Cu}$ and $0.18 \% \mathrm{Mg}$, $65.87 \% \mathrm{Al}, 29.18 \% \mathrm{Si}, 1.62 \% \mathrm{Fe}, 3.15 \% \mathrm{Cu}$.

The SEM imge in the aluminium piston block of the surface after 54 days of prolonged exposure in 3.5\% $\mathrm{NaCl}$ solution as shown in Figure 5(a), indicates that the surface composes of two regions. One is covered with grass like corrosion products from which the mushrooms were fromed and the other area is covered with a thin layer of corrosion products. The corresponding EDX profile analysis for the selected arrow point and square area of the SEM are shown in Figure 5(b) and Figure 5(c) respectively. The weight percentage of elements found in these areas were $56.38 \% \mathrm{O}, 1.84 \% \mathrm{Na} .5 .67 \% \mathrm{Mg}, 19.72 \% \mathrm{Al}, 14.49 \% \mathrm{Si}, 0.26 \% \mathrm{Cl}, 0.53 \% \mathrm{Fe}, 1.11 \%$ $\mathrm{Cu}$ and $82.36 \% \mathrm{O}, 1.42 \% \mathrm{Na}, 1.31 \% \mathrm{Mg}, 11.01 \% \mathrm{Al}, 1.71 \% \mathrm{Si}, 0.49 \% \mathrm{Cl}, 0.73 \% \mathrm{Ni}, 0.96 \% \mathrm{Cu}$. After 54 days of prolonged exposure in $3.5 \% \mathrm{NaCl}$ solution, it can be observed that the sample has been descaled as a consequence of fracturing of the surface film. The surface oxide film was observed to develop at an early period and increased in area and in thickness with the passage of time [5]. The development of this oxide film did not prevent the formation of cavities and large number of hemispherical micropits during prolonged exposure; these extends over a high proportion of the surface area.

The results obtained that, the aluminium alloy engine block in a $3.5 \% \mathrm{NaCl}$ solution suffers a process of localized corrosion. This process affects the zones of the matrix in contact with the intermetallics. The phenomena appears from the first day of exposure. It can be proposed that the presence of metallic inclusions more noble than the matrix reduces the resistance of the alloy to corrosion. These inclusions promote a process of anodic dissolution in the surrounding matrix by acting as cathode. The effect of the presence of $\mathrm{Al}_{3} \mathrm{Fe}$ inclusions on the corrosion behavior of the alloys revealed that the presence of $\mathrm{Al}_{3} \mathrm{Fe}$ precipitates increases the susceptibility of the alloy to pitting corrosion [9]. The behavior was attributed to the local increase in $\mathrm{pH}$ which is produced as a 

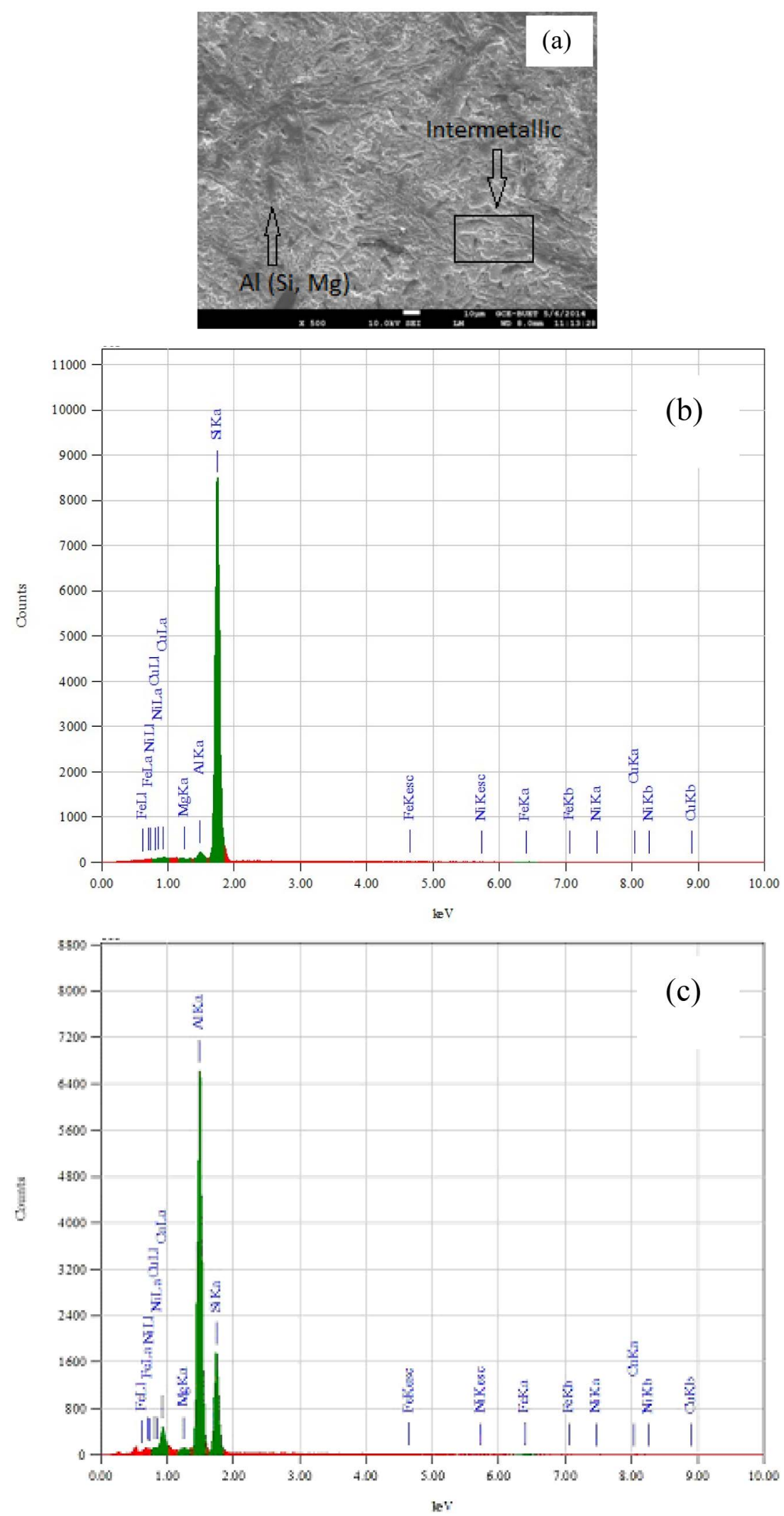

Figure 4. (a) SEM image and (b) and (c) EDX spectra recorded for different intermetallics identified in etched samples of aluminium alloy engine block before corrosion. 

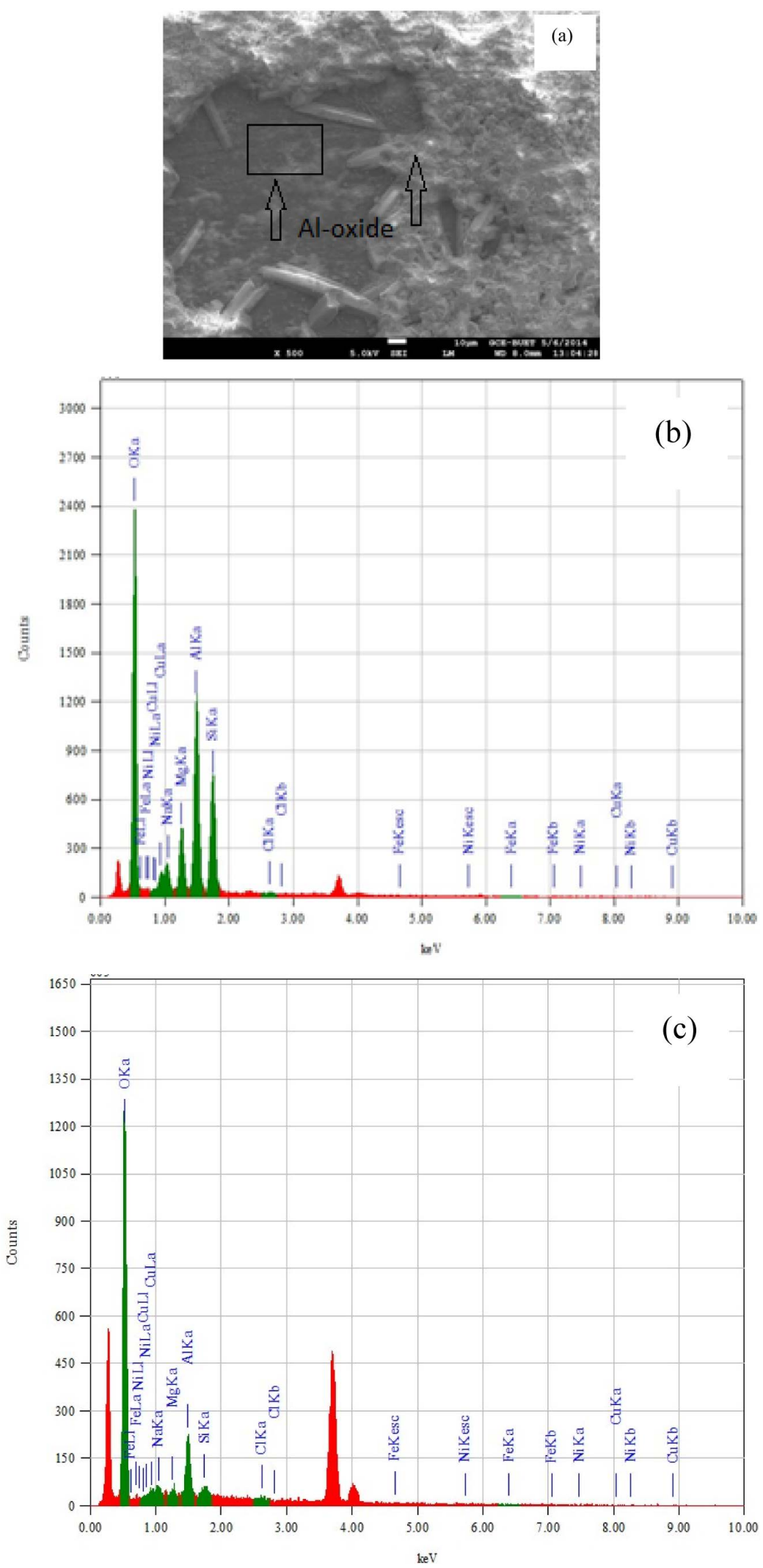

Figure 5. (a) SEM images and (b) and (c) EDX spectra obtained for samples of aluminium alloy engine block after exposure in a $3.5 \% \mathrm{NaCl}$ solution for 54 days. 
consequence of the reduction reaction of $\mathrm{O}_{2}$ and is indicated as a possible cause of the formation of pits around the intermetallic compounds.

\section{Conclusion}

From this study of the corrosion behavior of the aluminium alloy engine block in a 3.5\% NaCl solution, it can be concluded that, in function of the medium of exposure, this alloy undergoes localized corrosion process. The corrosion process was confirmed by gravimetric analysis where weight loss tests data after varied exposure periods showed that the weight loss of the alloy increases and the corrosion rate decreases with time. The corrosion process may lead to the formation of hemispherical and crystallographic pits. The alloy undergoes a process of corrosion localized to the area surrounding the precipitates of the $\mathrm{Al} \mathrm{(Si,} \mathrm{Mg)} \mathrm{and} \mathrm{Al}-\mathrm{Mg}$, which resulted in hemispherical pits. The corrosion may be related to the cathodic activity of these precipitates. The local increase in $\mathrm{pH}$ that is produced as a consequence of the reduction reaction would give rise to the local dissolution of the layer of the oxide and to the subsequent dissolution of matrix in contact with the precipitates. Under the condition of exposure, no evidence was found of the formation of crystallographic pitting for exposure times up to 54 days.

\section{Acknowledgements}

This work is supported by CASR of Bangladesh University of Engineering and technology and is part of project "Studies of recrystallization, wear and corrosion behavior of aluminium piston and piston block". Thanks to Department of Glass and Ceramics Engineering for providing the laboratory facilities.

\section{References}

[1] Evans, R.U. (1963) An Introduction to Metallic Corrosion. Edward Arnold Publishers, London.

[2] Smialowska, Z.S. (1986) Pitting Corrosion of Metals. NACE, Houston, TX.

[3] Mareus, P. and Oudart, J. (1995) Corrosion Mechanism in Theory and Practice. Marcel Dekker, New York.

[4] Sherif, E.M. (2012) Corrosion Behavior of Magnesium in Naturally Aerated Stagnant Seawater and 3.5\% Sodium Chloride Solutions. Int. J. Electrochem. Sci., 7, 4235-4249.

[5] Aballe, A., Bethencourt, M., Botana, F.J., Cano, M.J. and Marcos, M. (2001) Localized Alkaline Corrosion of Alloy AA5083 in Neutral 3.5\% NaCl Solution. Corrosion Science, 43, 1657-1674.

[6] Osorio, W.R., Cheung, N., Peixoto, L.C. and Garcia, A. (2009) Corrosion Resistance and Mechanical Properties of an Al 9wt\%Si Alloy Treated by Laser Surface Remelting. International Journal of Electrochemical Science, 4, 820-831.

[7] Sherif, E.M. and Almajid, A.A. (2011) Corrosion of Magnesium/Manganese Alloy in Chloride Solutions and Its Inhibition by 5-(3-Aminophenyl)-tetrazoleInt. International Journal of Electrochem. Science, 6, 2131-2148.

[8] Chaudhury, S.K., Warke, V., Shankar, S. and Apelian, D. (2011) Localized Recrystallization in Cast Al-Si-Mg Alloy during Solution Heat Treatment: Dilatometric and Calorimetric Studies. Metallurgical and Materials Transactions A, 42A, 3160-3169.

[9] Davoodi, A. (2008) Mechanistic Studies of Localized Corrosion of Al Alloys by High Resolution in-Situ and ex-Situ Probing Techniques. Ph.D. Thesis, Universitetsservice US-AB, Stockholm. 